\title{
Poly(2-cyclopropyl-2-oxazoline): From Rate Acceleration by Cyclopropyl to Thermoresponsive Properties
}

\author{
Meta M. Bloksma, ${ }^{+, \neq, \S}$ Christine Weber, ${ }^{\neq, \S}$ Igor Y. Perevyazko, ${ }^{\S}$ Anette Kuse, ${ }^{\S}$ Anja Baumgärtel, ${ }^{\ddagger, \S}$
}

Antje Vollrath, ${ }^{\S}$ Richard Hoogenboom, ${ }^{+, \perp, *}$ and Ulrich S. Schubert ${ }^{+,+, \S, *}$

\author{
${ }^{\dagger}$ Laboratory of Macromolecular Chemistry and Nanoscience, Eindhoven University of Technology, P.O. Box 513, 5600 MB Eindhoven, \\ The Netherlands \\ ${ }^{\ddagger}$ Dutch Polymer Institute (DPI), P.O. Box 902, 5600 AX Eindhoven, The Netherlands \\ ${ }^{\S}$ Laboratory of Organic and Macromolecular Chemistry (IOMC) and Jena Center for Soft Matter (JCSM), Friedrich-Schiller-University \\ Jena, Humboldtstrasse 10, 07743 Jena, Germany \\ ${ }^{\perp}$ Supramolecular Chemistry group, Department of Organic Chemistry, Ghent University, Krijgslaan 281 S4, 9000 Ghent, Belgium
}

Supporting Information

\begin{abstract}
The synthesis and microwave-assisted living cationic ring-opening polymerization of 2-cyclopropyl-2-oxazoline is reported revealing the fastest polymerization for an aliphatic substituted 2-oxazoline to date, which is ascribed to the electron withdrawing effect of the cyclopropyl group. The poly(2-cyclopropyl-2-oxazoline) (pCPropOx) represents an alternative thermo-responsive poly(2-oxazoline) with a reversible critical temperature close to body temperature. The cloud point (CP) of the obtained pCPropOx in aqueous solution was evaluated in detail by turbidimetry, dynamic light scattering (DLS) and viscosity measurements. pCPropOx is amorphous with a significantly higher glass transition temperature $\left(T_{\mathrm{g}} \sim 80{ }^{\circ} \mathrm{C}\right)$ compared to the amorphous poly(2-n-propyl-2-oxazoline) (pnPropOx) $\left(T_{\mathrm{g}} \sim 40^{\circ} \mathrm{C}\right)$, while poly(2-isopropyl-2-oxazoline) piPropOx is semicrystalline. In addition, a pCPropOx comb polymer was prepared by methacrylic acid end-capping of the living cationic species followed by RAFT polymerization of the macromonomer. The polymer architecture does not influence the concentration dependence of the $\mathrm{CP}$, however, both the $\mathrm{CP}$ and $\mathrm{T}_{\mathrm{g}}$ of the comb polymer are lower due to the increased number of hydrophobic end groups.
\end{abstract}

\section{INTRODUCTION}

There is a high potential for thermoresponsive polymers to be used in various applications, such as drug delivery systems ${ }^{1-5}$ and separation processes, ${ }^{6,7}$ and, therefore, these materials received significant attention over the last few years. Polymers that exhibit "lower critical solution temperature" (LCST) behavior are soluble in water below their $\operatorname{LCST}^{3,7,8}$ due to effective hydration of the polymer based on hydrogen bonds between the polymer and the solvent. With increasing temperature, the hydrogen bonds are weakened resulting in dehydration when the LCST is reached. This entropically driven phase transition, i.e., release of water molecules, leads to a collapse of the hydrophobic polymer chains and the formation of aggregates. Therefore, the LCST can be tuned, e.g., by variation of the polymer side chains or by copolymerization with other monomers, as fully explored for the most widely studied thermo-responsive polymer, poly $(N \text {-isopropylacrylamide) [PNIPAM }]^{3,6,9,10}$

Poly(2-oxazoline)s with methyl, ethyl, isopropyl, or $n$-propyl side chains are water-soluble and, except for the most hydrophilic poly(2-methyl-2-oxazoline) ( $\mathrm{pMeOx})$, show LCST behavior in water. $^{11,12}$ The cloud points (CP) of these poly(2-oxazoline)s increase with increasing hydrophilicity and depend on the degree of polymerization (DP) and concentration. ${ }^{13-15}$ The
CP can easily be tuned by copolymerization of various 2 -oxazoline monomers, as well as by controlling the length and end groups. ${ }^{16-19}$ Poly(2-ethyl-2-oxazoline) (pEtOx) is known to only reveal a CP when the DP is above 100 , since smaller polymer chains are soluble up to $100{ }^{\circ} \mathrm{C}$. ${ }^{15}$ Poly (2-isopropyl-2oxazoline) (piPropOx) is an interesting thermoresponsive polymer, since its CP is close to body-temperature, making it suitable for biomedical applications. ${ }^{20}$ However, due to its semicrystallinity the thermo-responsiveness becomes irreversible after annealing above the LCST. ${ }^{21-23} \operatorname{Poly}(2-n$-propyl-2-oxazoline) ( $n$ PropOx) is amorphous but has a lower LCST of $\sim 24{ }^{\circ} \mathrm{C} .{ }^{15}$ In addition, the rather low $T_{\mathrm{g}}$ of $\sim 40{ }^{\circ} \mathrm{C}$, which decreases in the presence of water, makes it difficult to handle and to store the polymer at ambient temperature. Therefore, an alternative thermo-responsive poly(2-oxazoline) with a reversible critical temperature close to body temperature is desired.

Besides linear poly(2-oxazoline)s, we recently also reported comb polymers containing oligo(2-ethyl-2-oxazoline) (OEtOx) sidechains and methacrylate (MA) backbone as thermo-responsive

Received: March 7, 2011

Revised: April 22, 2011

Published: May 12, 2011 


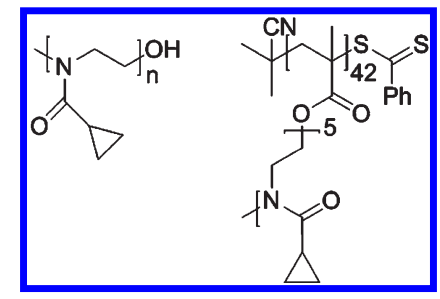

Figure 1. Schematic representation of the linear pCPropOx and the comb polymer $\mathrm{p}\left[(\mathrm{OCPropOx})_{5} \mathrm{MA}\right]_{42}$.

polymers. ${ }^{24}$ The utilized macromonomers are interesting because in combination with controlled radical polymerization techniques it is possible to introduce further functional moieties into the polymeric architecture, such as carboxylic acids that enable additional $\mathrm{pH}$ responsiveness. ${ }^{25}$ It is believed that the OEtOx side-chains shield the MA backbone resulting in a similar LCST behavior of the comb polymer compared to pEtOx, even though the absolute $\mathrm{CP}$ of the comb polymer is significantly lower than the CP of the linear polymer. ${ }^{24}$ Graft copolymers with a poly ( $N$-isopropylacrylamide) backbone and grafts containing EtOx and 2-(2-methoxycarbonylethyl)-2-oxazoline units are reported as well. Already small amounts of carboxylic groups stabilize the micelle formation in a broad temperature range. ${ }^{26}$ Furthermore, it is believed that the architecture of the polymer is important for its function as polymeric carrier. ${ }^{27}$

In this contribution, the synthesis of a new linear poly(2oxazoline), namely poly(2-cyclopropyl-2-oxazoline) (pCPropOx), and of the comb polymer, poly[(oligo-2-cyclopropyl-2oxazoline $)$ methacrylate $]$ (p [(OCPropOx $) \mathrm{MA}])$, containing OCPropOx side-chains and a MA backbone, are described (Figure 1). It is expected that due to the rigid and bulky ring structure of the cyclopropyl side-chains in pCPropOx an amorphous poly(2-oxazoline) is formed, while the $T_{\mathrm{g}}$ of $\mathrm{pCPropOx}$ is expected to be higher than pnPropOx. The LCST behavior of pCPropOx is discussed based on turbidity measurements, dynamic light scattering (DLS) and viscosimetry. Besides the influence of the molar mass and concentration on the critical temperature, also the influence of the polymer architecture is reported by comparing linear and comb polymers. Differential scanning calorimetry (DSC) measurements were used to determine the thermal properties of the polymers.

\section{EXPERIMENTAL SECTION}

Materials and Instrumentation. Cyclopropionitrile (Aldrich), 2 -aminoethanol (Aldrich), methacrylic acid (99\%, Aldrich) and the chain transfer agent 2-cyanopropan-2-yl dithiobenzoate (Aldrich, CPDB) were used as received. Acetonitrile (Aldrich) was dried in a solvent purification system (Pure Solv EN, Innovative Technology) before use as a polymerization solvent. Methyl tosylate (Aldrich) was distilled over barium oxide and stored under argon. Triethylamine $\left(\mathrm{NEt}_{3}\right)$ was distilled over potassium hydroxide and stored under argon. 2,2'-Azobis(2methylpropionitrile) (98\%, Acros, AIBN) was recrystallized from ethanol. All phase transitions were determined in demineralized water by turbidimetry, dynamic light scattering (DLS) and viscometry.

Small-scale reactions of $1 \mathrm{~mL}$ were carried out in capped reaction vials designed for the Biotage Sixty microwave system equipped with an IR temperature sensor. The vials were dried in the oven at $105^{\circ} \mathrm{C}$ and cooled under argon to room temperature before use.

${ }^{1} \mathrm{H}$ NMR and ${ }^{13} \mathrm{C}$ NMR spectra were recorded in $\mathrm{CDCl}_{3}$ on a Bruker Avance 250 or $300 \mathrm{MHz}$ spectrometer. Chemical shifts are given in ppm relative to TMS. GC measurements were performed on a Shimadzu GC-2010 equipped with a Restek Rtx-5 column, a FID detector and a PAL autosampler. ESI-Q-TOF-MS measurements were performed with a microTOF Q-II (Bruker Daltonics) mass spectrometer equipped with an automatic syringe pump from $\mathrm{KD}$ Scientific for sample injection. GC-MS measurements were performed on a Shimadzu GC-17A (Column: DB-SMS, 5\% phenyl-/95\% dimethylpolysiloxane, length = $30 \mathrm{~m}$, inner diameter $=0.25 \mathrm{~mm}$, film thickness $=0.1 \mu \mathrm{m}$ ) connected to an AOC-20i autoinjector and a GCMS-QP5050A mass spectrometer. Ionization was managed by EI (electron impact). MALDI-TOF spectra were recorded on an Ultraflex III TOF/TOF of Bruker Daltonics, Bremen, Germany equipped with a Nd:YAG laser and a collision cell. Size exclusion chromatography (SEC) was measured on a Shimadzu system equipped with a LC-10AD pump, a RID-10A refractive index detector, a SCL-10A VP system controller, and a PSS SDV pre/lin S column utilizing chloroform:triethylamine:2-propanol (94:4:2) as elu-

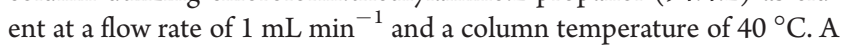
polystyrene (PS) or poly(methyl methacrylate) (PMMA) calibration was used to calculate the molar mass values. Turbidity measurements were performed on a Crystal 16 from Avantium Technologies connected to a chiller (Julabo FP 40) at a wavelength of $500 \mathrm{~nm}$. The concentration was systematically varied between 1 and $30 \mathrm{mg} \mathrm{mL}^{-1}$ in water. The transmittance was measured at a temperature range from 0 to $100{ }^{\circ} \mathrm{C}$ with heating and cooling rates of $1^{\circ} \mathrm{C} \mathrm{min}^{-1}$. The cloud point (CP) was defined as the temperature where the transmittance goes through $50 \%$. Dynamic light scattering (DLS) was performed on a Zetasizer Nano ZS of Malvern instruments, Malvern, U.K., equipped with a $10 \mathrm{~mW} \mathrm{He}-\mathrm{Ne}$ laser with a wavelength of $633 \mathrm{~nm}$, operating at an angle of $173^{\circ}$. The aqueous polymer solution with a concentration of $1 \mathrm{mg} \mathrm{mL}^{-1}$ was measured three times at different temperatures for $60 \mathrm{~s}$. The hydrodynamic radius $\left(R_{\mathrm{h}}\right)$ and polydispersity index $\left(\mathrm{PDI}^{\mathrm{DLS}}\right)$ was determined by the Cumulants method, assuming a spherical shape. Furthermore, the particle size distribution was obtained by the multi narrow mode. Viscosity measurements were conducted on an AMVn (Anton Paar, Graz, Austria) rolling ball viscometer with a manually filled capillary with an internal diameter of $0.8 \mathrm{~mm}$. The viscosity of the solution, $\eta$, and of the solvent, $\eta_{0}$, were obtained from the rolling times of the steel ball, measured at three inclination angles (from $30^{\circ}$ to $70^{\circ}$ ) of the capillary. The temperature dependence of the dynamic viscosity is described by the following equation:

$$
\eta(T)=\eta_{0} \exp \left(\frac{E}{R T}\right)
$$

The intrinsic viscosities of the polymer solutions at $20{ }^{\circ} \mathrm{C}$ were estimated according to the Kraemer extrapolation procedure:

$$
\frac{\ln \eta_{\mathrm{r}}}{\mathrm{c}}=[\eta]+k^{\prime \prime}[\eta]^{2} c+\ldots
$$

where $\eta_{\mathrm{r}}$ is the relative viscosity, $c$ is the concentration, and $k^{\prime \prime}$ is Kraemer's dimensionless parameter. For studying the temperature dependence, the dynamic viscosity was used.

Monomer Synthesis. The monomer has been synthesized by a standard procedure in which cyclopropionitrile ( 1 equiv) and zincacetate dehydrate (catalyst, 0.02 equiv) were heated to $130{ }^{\circ} \mathrm{C}$ under reflux conditions, and 2 -aminoethanol (1.1 equiv) was added dropwise. After a reaction time of $\sim 20 \mathrm{~h}$, the reaction mixture was allowed to cool to room temperature, and dichloromethane was added. The organic phase was washed 3 times with water and once with brine. After removing the dichloromethane under reduced pressure, the monomer was further purified by distillation over barium oxide. The monomer was analyzed with ${ }^{1} \mathrm{H}$ NMR and ${ }^{13} \mathrm{C}$ NMR spectroscopy as well as GC-MS and HR-ESI-MS to demonstrate the correct molecular structure. ${ }^{1} \mathrm{H}$ NMR $\left(250 \mathrm{MHz}, \delta\right.$ in ppm, $\left.\mathrm{CDCl}_{3}\right): 4.15\left(\mathrm{t}, \mathrm{CH}_{2} \mathrm{O}, 2 \mathrm{H}\right), 3.75\left(\mathrm{t}, \mathrm{CH}_{2} \mathrm{~N}, 2 \mathrm{H}\right)$, 1.6 (q, NCCH, 1H), 0.8 (br, $\left.\mathrm{CCHCH}_{2} \mathrm{CH}_{2}, 4 \mathrm{H}\right) .{ }^{13} \mathrm{C} \mathrm{NMR}(250 \mathrm{MHz}$, $\delta$ in ppm, $\left.\mathrm{CDCl}_{3}\right): 169.0(\mathrm{NC}=\mathrm{O}, 1 \mathrm{C}), 66.9\left(\mathrm{CH}_{2} \mathrm{O}=\mathrm{C}, 1 \mathrm{C}\right), 54.1$ 
$\left(\mathrm{NCCH}_{2}, 1 \mathrm{C}\right), 8.2(\mathrm{CCH}, 1 \mathrm{C}), 6.4\left(\mathrm{CH}\left(\mathrm{CH}_{2}\right)_{2}, 2 \mathrm{C}\right) . \mathrm{HR}-\mathrm{MS}$ (ESI-TOF): calculated for $\mathrm{C}_{6} \mathrm{H}_{9} \mathrm{NO}+\mathrm{H}^{+}=112.0757$; found $=$ 112.0759. GC-MS: $110\left[\mathrm{M}^{+}\right], 96\left[\mathrm{M}^{+}-\mathrm{CH}_{2}\right], 80\left[\mathrm{M}^{+}-\mathrm{C}_{2} \mathrm{H}_{4}\right]$, $68\left[\mathrm{M}^{+}-\mathrm{C}_{3} \mathrm{H}_{5}\right], 54\left[\mathrm{M}^{+}-\mathrm{C}_{4} \mathrm{H}_{7}\right], 41\left[\mathrm{M}^{+}-\mathrm{C}_{5} \mathrm{H}_{9}\right]$.

Kinetic Investigation of the Microwave-Assisted Polymerization. Kinetic investigations of the $\mathrm{CPropOx}$ polymerization were performed under microwave irradiation at $140{ }^{\circ} \mathrm{C}$ with an initial monomer concentration of $4 \mathrm{M}$ in acetonitrile and three monomer to initiator $([\mathrm{M}] /[\mathrm{I}])$ ratios of 52,107 , and 155 using methyl tosylate as the initiator. These conditions are similar to the previously reported conditions used for the polymerization of EtOx, $n$ PropOx, and $i$ PropOx. ${ }^{15,28}$

${ }^{1} \mathrm{H}$ NMR (300 MHz, $\left.\mathrm{CDCl}_{3}\right): \delta$ 3.8-3.1 ( $\mathrm{N}-\mathrm{CH}_{2}$; backbone); 3.2-3.0 ( $\mathrm{N}-\mathrm{CH}_{3}$; small initiator signals), $2.0-1.6(\mathrm{C}-\mathrm{CH}-\mathrm{C}$; c-propyl), $1.1-0.7\left(\mathrm{CH}_{2}-\mathrm{CH}_{2}, c\right.$-propyl $)$ ppm.

Polymer Synthesis. All polymers with varying $[\mathrm{M}] /[\mathrm{I}]$ values were synthesized under similar conditions. The initial monomer concentration $\left(M_{0}\right)$ was $4 \mathrm{M}$ for all polymerizations. The $[\mathrm{M}] /[\mathrm{I}](I=$ methyl tosylate) ratio was changed between 25 and 150 to obtain six polymers with varying degree of polymerization (DP). These polymerization mixtures were heated to $140^{\circ} \mathrm{C}$ under microwave irradiation for 1 to $5 \mathrm{~min}$, depending on the $[\mathrm{M}] /[\mathrm{I}]$ value, to reach $\sim 80 \%$ conversion. After cooling to $<40^{\circ} \mathrm{C}$, the polymerization mixtures were quenched by the addition of water. After drying under reduced pressure, the polymers were redissolved in chloroform and precipitated in cold $n$-hexane. The polymer was isolated by filtration followed by drying under reduced pressure, before further characterization. Turbidity measurements, dynamic light scattering (DLS), and viscosity measurements were carried out to determine the lower critical solution temperature (LCST). The thermal properties were determined by differential scanning calorimetry (DSC) measurements.

Comb Polymer Synthesis. The comb polymer was synthesized in a similar way as $\mathrm{p}[(\mathrm{OEtOx}) \mathrm{MA}]$, described in a recently published paper. ${ }^{24}$ In a representative example, MeOTs, CPropOx and acetonitrile with $\mathrm{M}_{0}$ of $4 \mathrm{~mol} \mathrm{~L}^{-1}$ and $[\mathrm{M}] /[\mathrm{I}]$ of 5 were heated to $140{ }^{\circ} \mathrm{C}$ under microwave irradiation for $20 \mathrm{~s}$. After cooling to $<40^{\circ} \mathrm{C}$, OCPropOx was end functionalized by the addition of 1.5-fold excess of MAA and 2-fold excess of $\mathrm{NEt}_{3}$ via syringe through the septum of the microwave vial. After completion of the reaction at $50{ }^{\circ} \mathrm{C}$ for $15 \mathrm{~h}$ the reaction mixture was dissolved in chloroform and washed with saturated aqueous sodium hydrogen carbonate and saturated brine, dried over sodium sulfate, and filtered. The solvent was evaporated under reduced pressure, and the resulting white sticky macromonomer was dried under reduced pressure. ${ }^{1} \mathrm{H}$ NMR $\left(300 \mathrm{MHz}, \mathrm{CDCl}_{3}\right): \delta 6.1\left(=\mathrm{CH}_{2}\right), 5.6\left(=\mathrm{CH}_{2}\right), 4.3$ $\left(\mathrm{CH}_{2}-\mathrm{COO}\right), 3.8-3.1\left(\mathrm{~N}-\mathrm{CH}_{2}\right) ; 3.2-3.0\left(\mathrm{~N}-\mathrm{CH}_{3}\right), \quad 2.0-1.6$
(C-CH-C), 1.1-0.7 $\left(\mathrm{CH}_{2}-\mathrm{CH}_{2}, c\right.$-propyl $)$ ppm. For the RAFT polymerization of the macromonomer, $1 \mathrm{~g}$ of OCPropOxMA was dissolved in ethanol and subsequently the appropriate amounts of CPDB (5.68 mg) and AIBN (1.05 mg) were added from stock solutions in ethanol. The monomer concentration was kept at $0.5 \mathrm{~mol} \mathrm{~L}^{-1}$ and the molar ratio of [monomer]:[CPDB]:[AIBN] at 60:1:0.25. In order to remove oxygen, an argon flow was bubbled through the solution for $30 \mathrm{~min}$ before the reaction was carried out in an oil bath at $70^{\circ} \mathrm{C}$ for $22 \mathrm{~h}$ (conversion $=70 \%$ ). The obtained polymer was precipitated into cold diethyl ether and, subsequently, dissolved in THF in order to separate unreacted OCPropOxMA monomer by column chromatography on a BioBeads S-X1 column (solvent THF, exclusion limit $14000 \mathrm{~g} / \mathrm{mol}$ ). Finally, the purified comb polymer was precipitated into cold diethyl ether and dried in a vacuum oven at $40^{\circ} \mathrm{C}$. Turbidity measurements of aqueous polymer solutions were carried out to determine the cloud point $(\mathrm{CP})$, to determine the thermal properties of the comb polymer, DSC measurements were performed.

\section{RESULTS AND DISCUSSION}

The monomer 2-cyclopropyl-2-oxazoline (CPropOx) could be synthesized by the reaction of cyclopropionitrile with 2 -amino-1-ethanol using zinc acetate as the catalyst following standard synthetic procedures. ${ }^{29}$ The polymerization kinetics of CPropOx was determined at $140{ }^{\circ} \mathrm{C}$, using an initial monomer concentration $\left(\mathrm{M}_{0}\right)$ of $4 \mathrm{M}$ and a monomer to initiator ratio $([\mathrm{M}] /[\mathrm{I}])$ of 52,107 , and 155 using methyl tosylate (MeOTs) as initiator and acetonitrile as solvent. The first order kinetics (Figure 2) do not pass the origin of the plots, indicating that the first data points in Figure $2 \mathrm{a}$ correspond to the conversions after $1 \mathrm{~s}$ reaction time at $140{ }^{\circ} \mathrm{C}$; i.e., the reaction already started while heating the reaction mixture to the reaction temperature of $140{ }^{\circ} \mathrm{C}$.

All three polymerizations of CPropOx revealed linear firstorder kinetics up to a conversion of approximately $80 \%$ as well as a linear increase of the molar mass with conversion, demonstrating a constant concentration of propagating species and that the polymerizations proceeded in a controlled manner. The polymerization rate constants $\left(k_{\mathrm{p}}\right)$ calculated from the linear fit up to $80 \%$ are $0.257( \pm 0.006) \mathrm{L} \mathrm{mol}^{-1} \mathrm{~s}^{-1}, 0.255( \pm 0.008) \mathrm{L} \mathrm{mol}^{-1}$ $\mathrm{s}^{-1}$ and $0.214( \pm 0.008) \mathrm{L} \mathrm{mol}^{-1} \mathrm{~s}^{-1}$ for $[\mathrm{M}] /[\mathrm{I}]=52,[\mathrm{M}] /[\mathrm{I}]$ $=107$ and $[\mathrm{M}] /[\mathrm{I}]=155$, respectively. These similar $k_{\mathrm{p}}$ values confirm that the polymerization proceeded in a controlled fashion. Compared to other 2-oxazolines, CPropOx polymerizes approximately two times faster under similar conditions; the $k_{\mathrm{p}}$ of

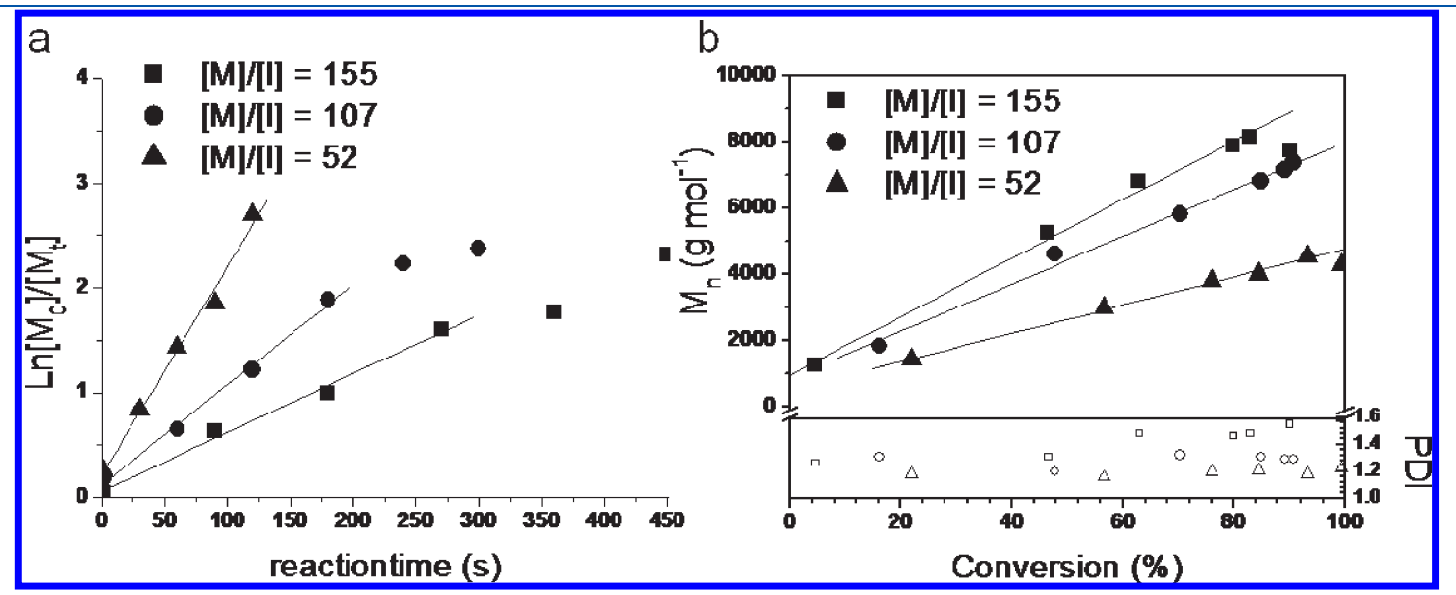

Figure 2. (a) Kinetic plots for CPropOx polymerizations initiated with methyl tosylate $([\mathrm{M}] /[\mathrm{I}]=52,107$, and 155$)$ in acetonitrile $\left(M_{0}=4 \mathrm{M}\right)$ at $140{ }^{\circ} \mathrm{C}$. (b) Corresponding molar mass $\left(M_{\mathrm{n}}\right)$ against conversion plot, including polydispersity indices (PDI). 


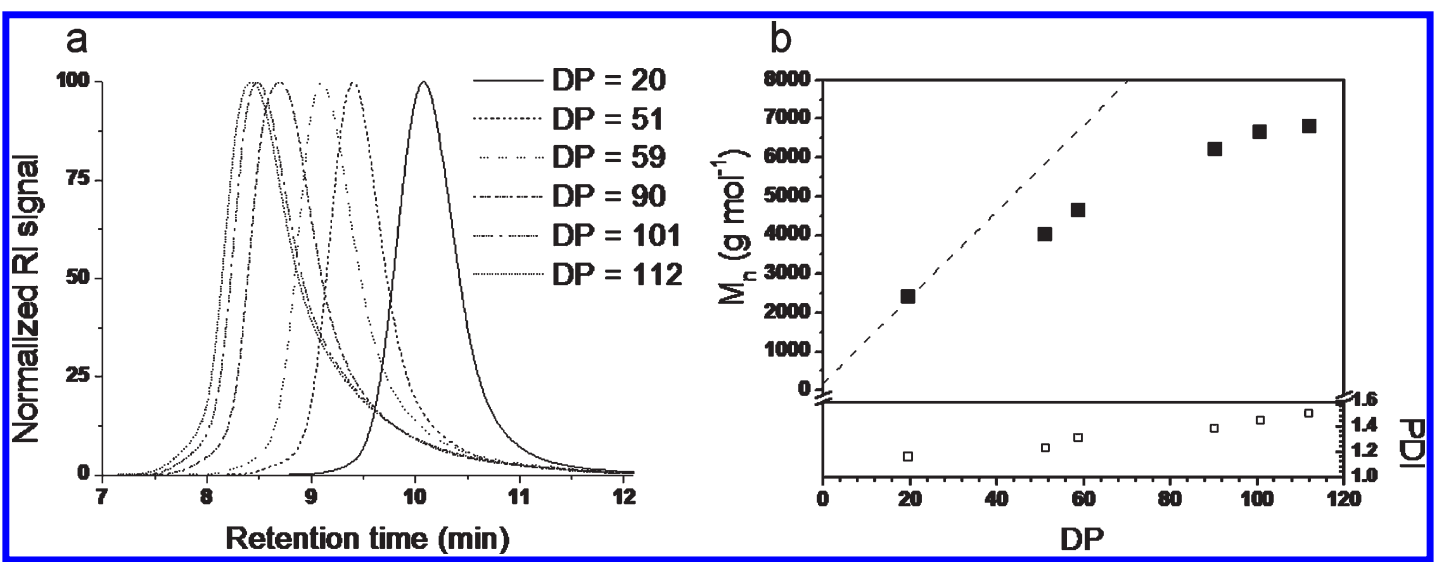

Figure 3. (a) SEC traces of all six synthesized polymers dissolved in chloroform. (b) Molar mass and polydispersity indices (PS calibration) plotted against the calculated degree of polymerization (DP). The dashed line represents the theoretical molar mass.

$n$ PropOx is $0.117( \pm 0.004) \mathrm{L} \mathrm{mol}^{-1} \mathrm{~s}^{-1,30}$ while in contrast $i$ PropOx polymerizes slower than $n$ PropOx. ${ }^{18}$ In fact, the $k_{\mathrm{p}}$ of CPropOx is the fastest reported so far for a 2-oxazoline with an aliphatic side chain; only 2-phenyl-2-oxazolines with electronwithdrawing $o$-fluoro groups were slightly faster. ${ }^{31}$ The higher reactivity of CPropOx is not yet completely understood, but might be related to the electron withdrawing effect of the cyclopropyl substituent caused by the small angle of $60^{\circ}$ between the $\mathrm{C}$ atoms resulting in partial $\pi$-character of the bonds making the remaining orbitals s-rich and, thus, electron withdrawing. ${ }^{32}$ Even though this electron withdrawing effect lowers the nucleophilicity of the monomer, it enhances the reactivity of the cationic propagating species apparently dominating the overall polymerization rate. The lower steric bulk of cyclopropyl compared to $n$-propyl or isopropyl most likely does not influence the polymerization rate since it has been demonstrated that 2-oxazolines with ethyl to $n$-nonyl substituents all have similar polymerization rates. ${ }^{30}$ At higher conversion (>80\%), the solution became very viscous explaining the observed decrease in polymerization rate due to limited diffusion. This can also explain the slightly slower polymerization rate at higher $[\mathrm{M}] /[\mathrm{I}]$ ratios due to the higher viscosity resulting from longer polymer chains. In addition, SEC characterization revealed monomodal molar mass distributions for the polymers with polydispersity index (PDI) values below 1.3 when the $[\mathrm{M}] /[\mathrm{I}]$ ratio is 52 or 107 demonstrating that the polymers were prepared in a controlled manner. At a higher $[\mathrm{M}] /[\mathrm{I}]$ ratio, the PDI values start to increase indicating the occurrence of more chain transfer reactions. It is known that the control over the polymerization is lost for most poly(2oxazoline)s when the $[\mathrm{M}] /[\mathrm{I}]$ value is above $200 .{ }^{33}$

On the basis of the kinetic investigations, six CPropOx polymers with different degrees of polymerization (DP) were synthesized under microwave-assisted conditions using MeOTs as initiator and acetonitrile as solvent. The $\mathrm{DP}$ values were calculated from the conversion measured by GC, assuming the absence of chain transfer and termination reactions. After the polymerization, the polymers were precipitated in $n$-hexane resulting in white solid powders. Most polymers show some tailing in the SEC traces (Figure 3), indicating the occurrence of some chain transfer and/or termination reactions during the polymerization. When $M_{n}$ (determined with SEC) is plotted against DP (calculated from the GC results), it is observed that the values progressively deviate from the theoretical values with increasing DP. This increasing deviation is a direct consequence of the broadening of the molar mass distributions, ascribed to chain transfer reactions, causing a decrease in $M_{n}$. It should be noted that this effect might be overestimated by the used SEC calibration standards.

The MALDI-TOF MS (Figure 4a) spectrum of pCPropOx with a DP of 20 revealed two main distributions corresponding to the methyl initiated pCPropOx $\left(\mathrm{CH}_{3}\left[\mathrm{C}_{6} \mathrm{H}_{9} \mathrm{NO}\right]_{n} \mathrm{OH}\right)$ and the proton initiated pCPropOx $\left(\mathrm{H}\left[\mathrm{C}_{6} \mathrm{H}_{9} \mathrm{NO}\right]_{n} \mathrm{OH}\right)$, confirming the expected polymer structure as well as indicating the occurrence of minor chain transfer reactions leading to the proton initiated chains (ESI).

Besides linear pCPropOx, also a comb CPropOx polymer was synthesized to demonstrate the versatility of the CPropOx monomer as well as to investigate the influence of the polymeric architecture on the polymer properties. During the macromonomer synthesis, a well-defined oligo(2-cyclopropyl-2-oxazoline)methacrylate (OCPropOxMA) with a DP of 5 was obtained by end-capping the living polymer chains with triethylammonium methacrylate. The macromonomer has a molar mass of $750 \mathrm{~g} /$ mol and a PDI value of 1.17 (SEC using PS standards, ESI). The MALDI-TOF MS spectrum revealed that next to the desired compound $\left(\mathrm{CH}_{3}\left[\mathrm{C}_{6} \mathrm{H}_{9} \mathrm{NO}\right]_{n} \mathrm{C}_{4} \mathrm{H}_{5} \mathrm{O}_{2}\right)$, also two minor mass distributions are present that can be assigned to proton initiated $\left(\mathrm{H}\left[\mathrm{C}_{6} \mathrm{H}_{9} \mathrm{NO}\right]_{n} \mathrm{C}_{4} \mathrm{H}_{5} \mathrm{O}_{2}\right)$ and water end-capped polymer chains $\left(\mathrm{CH}_{3}\left[\mathrm{C}_{6} \mathrm{H}_{9} \mathrm{NO}\right]_{n} \mathrm{OH}\right)$ (Figure $4 \mathrm{~b}, \mathrm{ESI}$ ). Comparison of the peak integrals derived from the vinylic protons of the MA end group and aromatic protons of the tosylate counterion in the ${ }^{1} \mathrm{H}$ NMR spectrum of the reaction mixture revealed a degree of functionalization of $91 \%$ with the desired MA end group (ESI). In the second step, the macromonomer was polymerized via reversible addition-fragmentation chain transfer (RAFT) polymerization up to a conversion of $70 \%$, as determined from the integrals of the macomonomer and the polymer in the SEC curve (ESI), resulting in a comb polymer with a theoretical DP of 42 and a theoretical molar mass of 27,500 $\mathrm{g} \mathrm{mol}^{-1}$ (estimated from [M]:[CTA] and conversion). As frequently observed for polymacromonomers, the molar mass determined by SEC (9400 $\mathrm{g} \mathrm{mol}^{-1}$ ), is significantly underestimated as a result of the large difference in hydrodynamic volume of the dense "bottle brush" like polymer structure when compared to the linear PMMA standards. Nevertheless, SEC reveals a narrow and symmetric molar mass distribution with a PDI value of 1.19 (ESI) as well as a complete removal of residual macromonomer after purification by preparative SEC using Biobeads. 


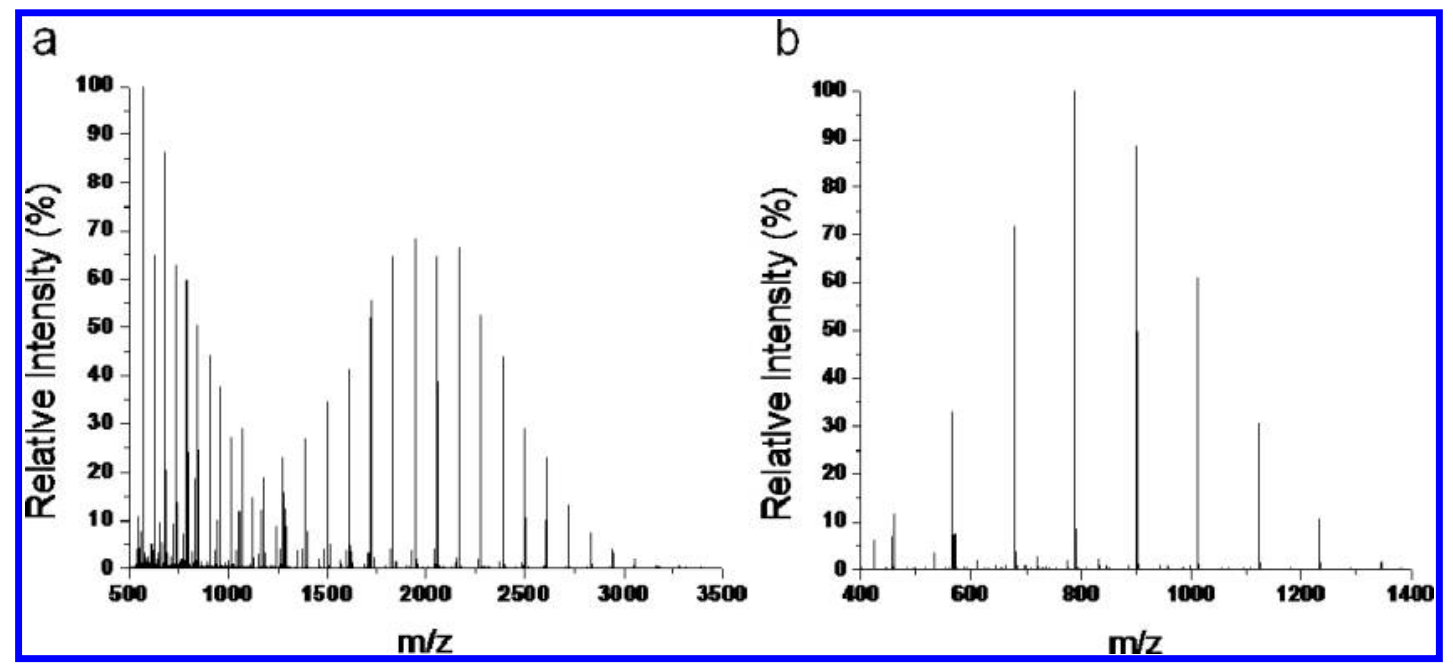

Figure 4. MALDI-TOF MS spectrum of (a) pCPropOx with DP $=20$ and (b) the macromonomer, OCPropOxMA, using DCTB as the matrix.

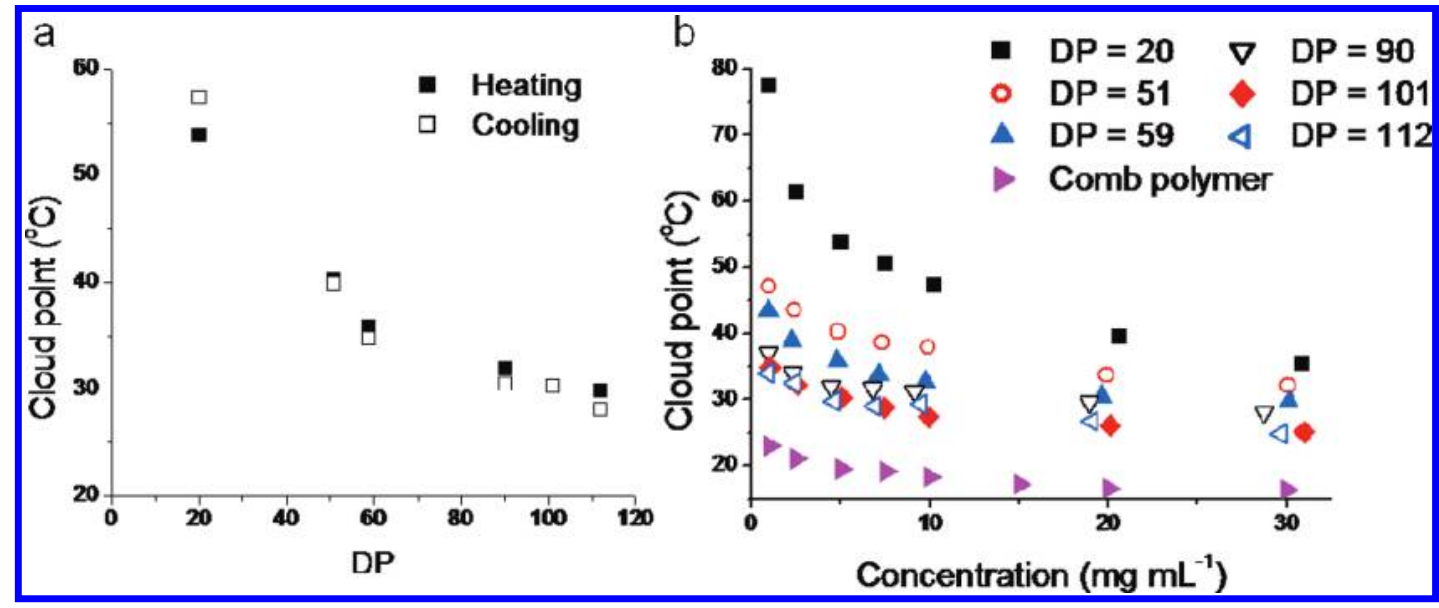

Figure 5. (a) Cloud points (CPs) determined by turbidimetry as a function of the degree of polymerization (DP) of pCPropOx at a concentration of $5 \mathrm{mg} \mathrm{mL} L^{-1}$ in water. (b) CPs as a function of concentration for $\mathrm{pCPropOx}$ with various DP and $\mathrm{p}\left[(\mathrm{OCPropOx})_{5} \mathrm{MA}\right]_{42}$.

Turbidity of the aqueous pCPropOx polymer solutions was measured as a function of temperature with a concentration of $5 \mathrm{mg} \mathrm{mL}^{-1}$ with heating and cooling rates of $1^{\circ} \mathrm{C} \mathrm{min}^{-1}$ in a temperature range between 0 and $100{ }^{\circ} \mathrm{C}$. Upon heating, the polymer precipitates resulting in a drop in transmittance, and, upon cooling, the polymer dissolves again demonstrating the reversibility of the solubility transition. Most polymers show similar transmittance curves during heating and cooling indicating that no or only a slight hysteresis took place (ESI), except for pCPropOx with a DP of 20. The reason for this larger hysteresis is unsure, but it might be related to the formation of smaller aggregates that cannot be detected by turbidimetry. The cloud points (CP) taken from the first heating run decrease in a nonlinear way from $54{ }^{\circ} \mathrm{C}$ for pCPropOx with a DP of 20 to $30{ }^{\circ} \mathrm{C}$ for pCPropOx with a DP of 112 (Figure 5a). The steepest decrease occurs when the DP is increased from DP $=20$ to $\mathrm{DP}=51$, which is due to the end group effect which is more pronounced in short polymers. Since the $-\mathrm{OH}$ end group is more hydrophilic than the polymer chain, the end group will increase the CP. With the increase in concentration, the CP decreases in a nonlinear way and only a small decrease is observed when the concentration is increased from 10 to
$30 \mathrm{mg} \mathrm{mL}^{-1}$ indicating that the $\mathrm{CP}$ at $30 \mathrm{mg} \mathrm{mL}^{-1}$ approaches the LCST value (Figure 5b). Both the DP and concentration dependence of the CP follow the same trend as for $\mathrm{p} n \mathrm{PropOx},{ }^{15}$ which is a consequence of the Type I Flory-Huggins miscibility behavior that is characterized by a shift of the LCST toward lower polymer concentration when the polymer chain length is increased. ${ }^{34}$ The CP of pCPropOx $\left(30^{\circ} \mathrm{C}\right)$ lies in between the $\mathrm{CP}$ of pnPropOx $\left(44^{\circ} \mathrm{C}\right)$ and piPropOx $\left(27^{\circ} \mathrm{C}\right)\left(\right.$ all $5 \mathrm{mg} \mathrm{mL}^{-1}$ and a DP of 100, ESI). This can be explained by the difference in hydrophilicity; ${ }^{35}$ the polymer that is most hydrophilic (pEtOx) has the highest CP followed by piPropOx, pCPropOx, and $\mathrm{p} n$ PropOx.

Like pCPropOx, the comb polymer does not show large hysteresis; the CP during heating is comparable to the CP during cooling (ESI). The concentration dependence of the CP of the comb polymer follows the same trend as for linear pCPropOx (Figure 5b), which is in contrast to the concentration dependence of poly(2-oxazoline)s with different cloud points due to different side chains, such as pEtOx and pnPropOx. ${ }^{15}$ This confirms that the side-chains shield the MA backbone and that only the OCPropOx side-chains interact with the aqueous environment, resulting in similar LCST behavior for the linear 


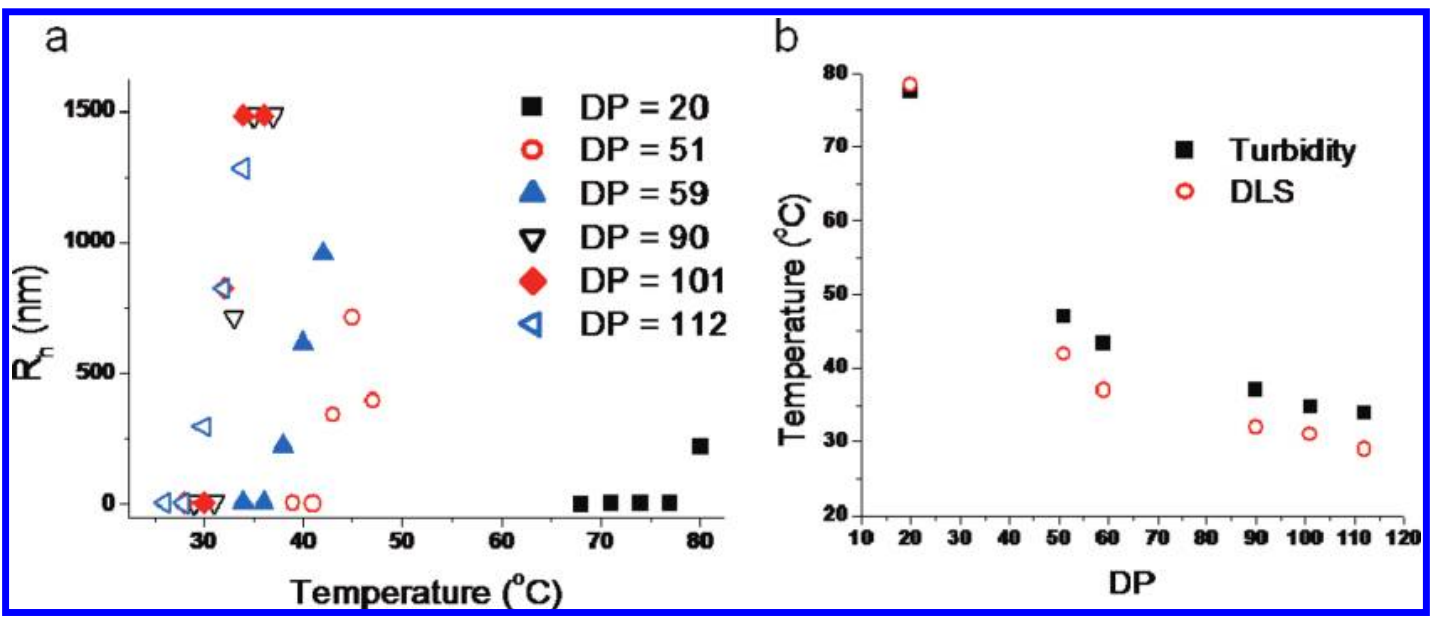

Figure 6. (a) Hydrodynamic radius $\left(R_{\mathrm{h}}\right)$ of the particles/aggregates against temperature measured with DLS of pCPropOx at a concentration of 1 $\mathrm{mg} \mathrm{mL} \mathrm{m}^{-1}$ dissolved in water. (b) Comparison of the critical temperature measured with turbidity measurements and DLS.

and comb pCPropOx. However, the CP's of the comb polymer are decreased by $\sim 10{ }^{\circ} \mathrm{C}$ when compared to linear pCPropOx, which may be a result of the large number of $-\mathrm{CH}_{3}$ end groups at the pendant side chains of the comb structure as well as the high local polymer concentration. These hydrophobic $\mathrm{CH}_{3}$ moieties point toward the outside of the "bottle brush" structure in solution and might therefore facilitate the agglomeration of the collapsed macromolecules upon their coil to globule transition. Those findings are in good agreement with previous observations for the LCST behavior of comb shaped pEtOx when compared to its linear analogue. ${ }^{24,35}$

The formation of aggregates of $\mathrm{pCPropOx}$ with varying DP was investigated in further detail by dynamic light scattering (DLS) measurements at a concentration of $1 \mathrm{mg} \mathrm{mL}^{-1}$ at different temperatures. At a certain temperature the hydrodynamic radius $\left(R_{\mathrm{h}}\right)$ measured by DLS increases from the characteristic size of individual polymer chains $(<10 \mathrm{~nm})$ to the size of larger aggregates (>100 nm) (Figure $6 a$ and ESI). The detection of the formation of aggregates takes place $\sim 5{ }^{\circ} \mathrm{C}$ below the $\mathrm{CP}$ measured by turbidimetry (Figure $6 \mathrm{~b}$ ). The basis of this difference is 3-fold: (1) DLS detects the scattering of any form of aggregation while turbidimetry only detects large aggregates that can scatter the light, (2) the CP from turbidimetry is defined as $50 \%$ transmittance while the onset of aggregates is taken as CP for the DLS measurements, and (3) DLS is measured in steady state while turbidimetry is performed with a heating rate of $1 \mathrm{~K} / \mathrm{min}$. The only exception is pCPropOx with a DP of 20; at $77{ }^{\circ} \mathrm{C}$ the $R_{\mathrm{h}}$ of the particles are still $<10 \mathrm{~nm}$, while according to the turbidity measurements the solution becomes turbid at this temperature. Nonetheless, at $80{ }^{\circ} \mathrm{C}$ two distributions are also found in the DLS for pCPropOx with a DP of 20 (ESI), indicating that larger aggregates with a size of $>300 \mathrm{~nm}$ are formed. This discrepancy might be due to inaccuracies in the temperature calibrations at higher temperatures.

When the critical temperature is approached, also the viscosity of the solution will change providing an additional possibility to investigate the thermo-responsive behavior. ${ }^{36}$ The measured values of intrinsic viscosities $[\eta]$ at ambient conditions $\left(T=20^{\circ} \mathrm{C}\right)$ are as follows: $[\eta]=4.6,8.2$, and $11.6 \mathrm{~cm}^{3} \cdot \mathrm{g}^{-1}$, for pCPropOx with a DP of 20,59 and 101, respectively. The LCST behavior of the polymers was investigated at different highly diluted concentrations where the Debye parameter $c[\eta]$, which characterizes the degree of dilution, was in the range of $(0.008 \pm 0.003) \leq c[\eta] \leq$ $(0.24 \pm 0.15)$. There are several regions that can be considered within the temperature dependence of the viscosity. At first, when the temperature starts to increase, the dynamic viscosity $(\eta)$ of the solution decreases according to eq 1 (Figure 7). When the critical temperature is approached, the viscosity increases due to deterioration of the solvent quality and more favorable interactions between the polymer chains. As a result, intermolecular interactions occur leading to the formations of clusters, which then subsequently merge together into large aggregates. Increasing the temperature further leads to the collapse of the polymer chains resulting in precipitation of the polymer and consequently to a reduction of the viscosity values. This behavior is most pronounced in pCPropOx with a DP of 51 at a low concentration $\left(1 \mathrm{mg} \mathrm{mL}^{-1}\right)$, since this polymer has an intermediate viscosity and a relatively low critical temperature.

The critical temperatures determined by viscosity measurements, identified as the midpoint on a tangent line to the straight section of the curve, compare well with the CP measured by turbidity measurements for pCPropOx with a DP of 59 and 101. However, the viscosity measurements of $\mathrm{pCPropOx}$ with a DP of 20 indicated a higher critical temperature compared to turbidity measurements due to the low molar mass resulting in minimal viscosity changes, especially at these low concentrations. At $1 \mathrm{mg} \mathrm{mL}^{-1}$, the viscosity measurements underestimated the critical temperature for all three investigated polymers due to the low concentration and, thus, minimal chain overlap in solution.

The previously discussed investigations clearly reveal the high potential of pCPropOx for biomedical applications based on the $\mathrm{CP}$ in between body- and ambient temperature as well as the low hysteresis. The thermal properties of the polymers are also very important for the ease of storage, i.e. for pharmaceutical applications storage should be at least $40{ }^{\circ} \mathrm{C}$ below $T_{\mathrm{g}}$, and for the reversibility of the phase-transition an amorphous polymer is required, i.e. absence of polymer crystallization upon annealing of the solution, as observed for piPropOx. The differential scanning calorimetry (DSC) data (Figure 8) demonstrate that pCPropOx is amorphous since it does not reveal a melting endotherm $\left(T_{\mathrm{m}}\right)$ up to $300{ }^{\circ} \mathrm{C}$. A glass transition temperature $\left(T_{\mathrm{g}}\right)$ at $79{ }^{\circ} \mathrm{C}$ was observed with a heat capacity $\left(\Delta \mathrm{C}_{\mathrm{p}}\right)$ of 0.4 $\mathrm{Jg}^{-1} \mathrm{~K}^{-1}$. The polymer with a relatively low molar mass $(\mathrm{DP}=26)$ has a lower $T_{\mathrm{g}}$ at $75{ }^{\circ} \mathrm{C}$, due to the increased fraction of flexible 


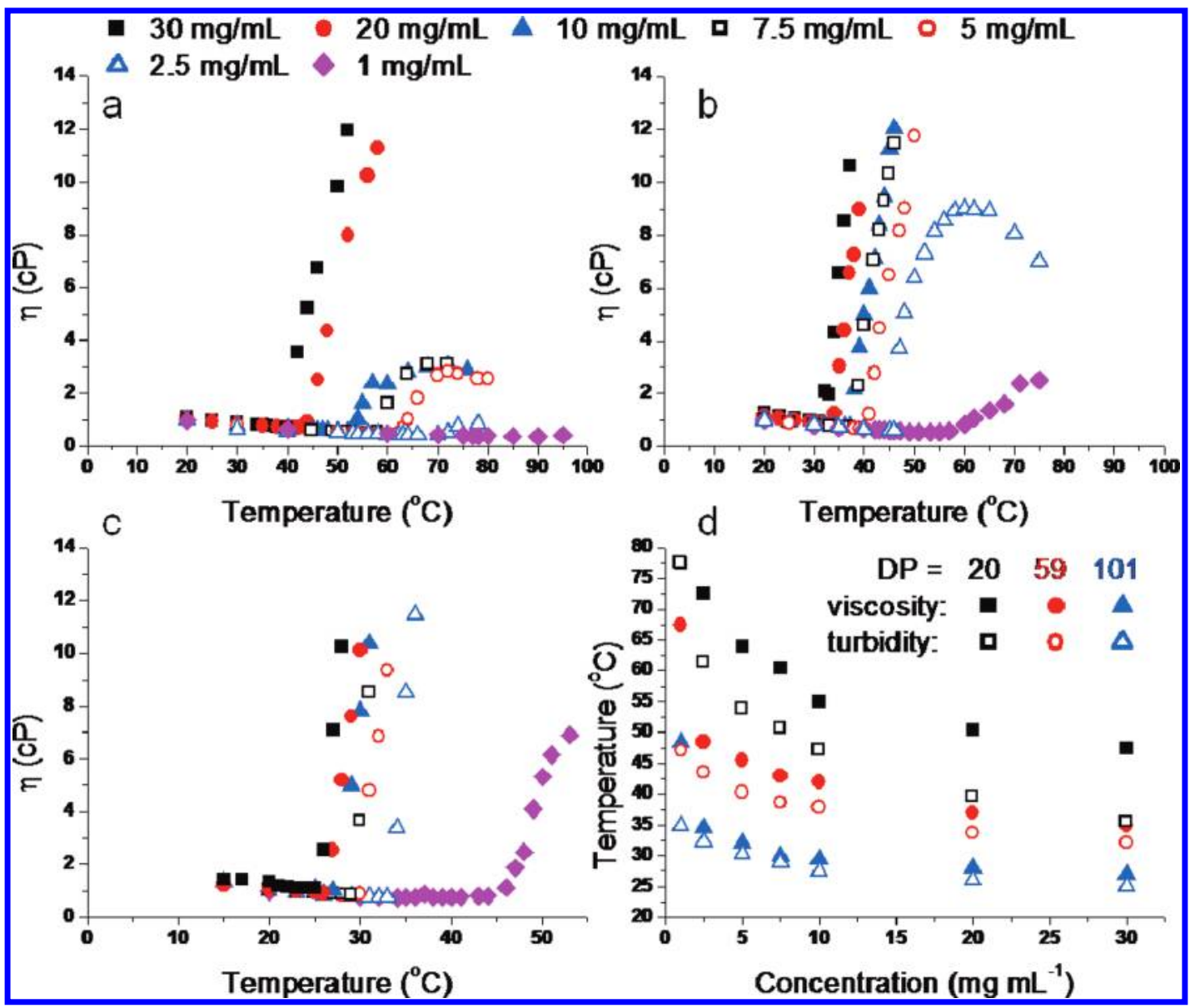

Figure 7. Dynamic viscosity $(\eta)$ against temperature for pCPropOx with a DP of (a) 20, (b) 51, and (c) 101. (d) Comparison of the critical temperature determined with turbidity and viscometry against the concentration.

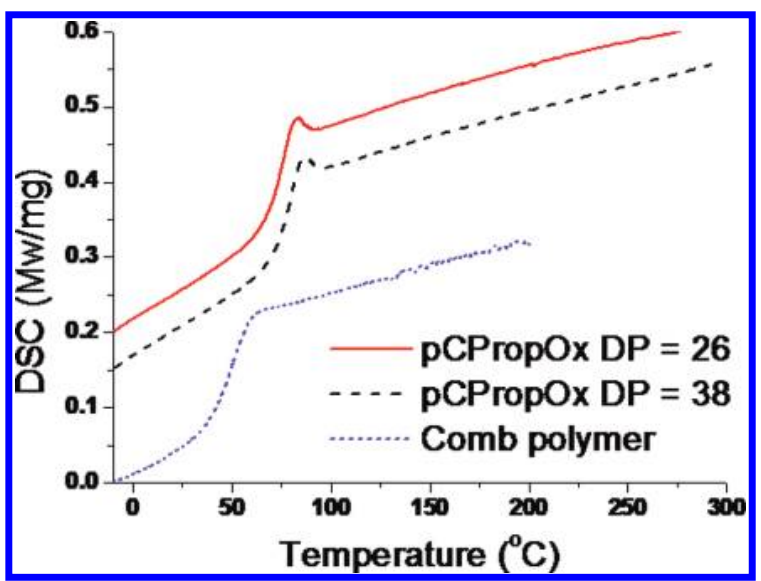

Figure 8. DSC traces of the second heating run $\left(20^{\circ} \mathrm{C} \min ^{-1}\right)$ of pCPropOx with different molar masses and the comb polymer, $\mathrm{p}\left[(\mathrm{OCPropOx})_{5} \mathrm{MA}\right]_{42}$.

chain ends. The $T_{\mathrm{g}}$ of the comb polymer is $\sim 25^{\circ} \mathrm{C}$ below the $T_{\mathrm{g}}$ of the linear pCPropOx, as a result of the increased number of chain ends causing an increase in the free volume. ${ }^{37}$

\section{CONCLUSIONS}

CpropOx could be synthesized via the reaction of cyclopropionitrile with 1-amino-2-ethanol. A kinetic investigation on the CROP of CPropOx revealed that the polymerization took place in a controlled fashion with a polymerization rate constant in the range of $0.214( \pm 0.008)$ to $0.257( \pm 0.006) \mathrm{L} \mathrm{mol}^{-1} \mathrm{~s}^{-1}$, which is the highest reported value for an aliphatic substituted 2-oxazoline monomer so far. This observed rate acceleration is ascribed to the electron withdrawing effect of the cyclopropyl group. The formation of well-defined polymers was confirmed by SEC and MALDI-TOF MS measurements. A well-defined comb polymer based on CPropOx side-chains and a methacrylate backbone could be synthesized via the macromonomer route comprising CROP and RAFT demonstrating the versatility of the CPropOx monomer. The CP of linear pCPropOx decreases with both increasing DP and increasing concentration, which is typical for Type I Flory-Huggins miscibility behavior. With a CP of $25{ }^{\circ} \mathrm{C}$ for pCPropOx with a DP >100 at 30 $\mathrm{mg} \mathrm{mL}^{-1}$, the CP is slightly higher compared to $\mathrm{p} n \mathrm{PropOx}$. The $\mathrm{CP}$ of the comb polymer reveals the same concentration dependence as linear pCPropOx, although the absolute cloud point is at a lower temperature due to the increased amount of hydrophobic end groups and the high local polymer concentration. DLS indicated the formation of aggregates approximately $5{ }^{\circ} \mathrm{C}$ below the $\mathrm{CP}$ measured by turbidimetry due to its higher sensitivity, and the critical temperatures determined with viscometry compare well with the CPs from turbidimetry. Furthermore, DSC measurements revealed that both the linear pCPropOx $\left(T_{\mathrm{g}}=\right.$ $\sim 80{ }^{\circ} \mathrm{C}$ ) as well as the comb polymer $\left(T_{\mathrm{g}}=\sim 25{ }^{\circ} \mathrm{C}\right)$ are amorphous. 
In this work a new class of thermo-responsive poly(2-oxazoline)s based on CPropOx is presented, which has a slightly higher CP compared to pnpropOx and is amorphous in contrast to piPropOx. Besides a linear $\mathrm{pCPropOx}$, also a thermo-responsive comb polymer containing OCPropOx side-chains on a MA backbone was described. On the basis of the amorphous nature and desirable $T_{\mathrm{g}}$, these $\mathrm{pCPropOx}$ have a great potential as materials for biomedical applications.

\section{ASSOCIATED CONTENT}

S Supporting Information. Reaction scheme for $\mathrm{p}$ [(OCProp$\left.\mathrm{Ox})_{5} \mathrm{MA}\right]$, MALDI-TOF MS isoptopic patterns and assignments, SEC and ${ }^{1} \mathrm{H}$ NMR spectra for OCPropOxMA and $\mathrm{p}\left[(\mathrm{OCPropOx})_{5} \mathrm{MA}\right]$, and turbidity curves as well as DLS curves. This material is available free of charge via the Internet at http://pubs.acs.org/.

\section{AUTHOR INFORMATION}

\section{Corresponding Author}

*E-mail: (R.H.) richard.hoogenboom@ugent.be; (U.S.S.) ulrich. schubert@uni-jena.de.

\section{ACKNOWLEDGMENT}

The authors thank the Dutch Polymer Institute (DPI) for financial support, Esra Altuntas for the HR-ESI measurement, Dr. Uwe Köhn for support during the synthesis of the new monomer and Dr. George M. Pavlov as well as Dr. Stephanie Schubert for their helpful comments. RH (VENI-award) and USS (VICI-award) are grateful to The Netherlands Scientific Organisation (NWO) for financial support.

\section{REFERENCES}

(1) Li, G.; Guo, L.; Ma, S. I.Appl. Polvm. Sci. 2009, 113, 1364-1368.

(2) Wei., H.; Cheng, S.-X.; Zhang, X.-Z.; Zhuo, R.-X. Prog. Polym. Sci. 2009, 34, 893-910.

(3) Liu, R.; Fraylic, M.; Saunders, B. R. Colloid Polym. Sci. 2009, 287, 627-643.

(4) Schmaljohann, D. Adv. Drug Deliverv Rev. 2006, 58, 1655-1670.

(5) Roy, D.; Cambre, J. N.; Sumerlin, B. S. Prog. Polym. Sci. 2010, $35,278-301$.

(6) Schild, H. G. Prog. Polvm. Sci. 1992, 17, 163-249.

(7) Gil, E. S.; Hudson, S. M. Prog. Polvm. Sci. 2004, 29, 1173-1222.

(8) Chen, F. P.; Ames, A. E.; Taylor, L. D. Macromolecules 1990, 23, 4688-4695.

(9) Crespy, D.; Rossi, R. N. Polvm. Int. 2007, 56, 1461-1468.

(10) Yu, B.; Chan, J. W.; Hoyle, C. E.; Lowe, A. B. J. Polym. Sci., Part A: Polvm. Chem. 2009, 47, 3544-3557.

(11) Adams, N.; Schubert, U. S. Adv. Drug Delivery Rev. 2007, 59, 1504-1520.

(12) Hoogenboom, R. Angew. Chem. Int. Ed. 2009, 48, 7978-7994.

(13) Lin, P.; Clash, C.; Pearce, E.; Kwei, T. K. J. Polym. Sci., Part B: Polvm. Phys. 1988, 26, 603-619.

(14) Christova, D.; Velichkova, R.; Loos, W.; Goethals, E.; Du Prez, F. Polymer 2003, 44, 2255-2261.

(15) Hoogenboom, R.; Thijs, H. M. L.; Jochems, M. J. H. C.; van Lankvelt, B. M.; Fijten, M. W. M.; Schubert, U. S. Chem. Commun. 2008, 5758-5760.

(16) Huber, S.; Hutter, N.; Jordan, R. Colloid Polym. Sci. 2008, 286, 1653-1661.

(17) Huber, S.; Jordan, R. Colloid Polvm. Sci. 2008, 286, 395-402.

(18) Park, J.-S.; Kataoka, K. Macromolecules 2007, 40, 3599-3609.
(19) Diehl, C.; Schlaad, H. Macromol. Biosci. 2009, 9, 157-161.

(20) Park, J.-S.; Akiyama, Y.; Winnik, F. M.; Kataoka, K. Macromolecules 2004, 37, 6786-6792.

(21) Meyer, M.; Antonietti, M.; Schlaad, H. Soft Matter 2007, 3, 430-431.

(22) Demirel, A. L.; Meyer, M.; Schlaad, H. Angew. Chem., Int. Ed. 2007, 46, 8622-8624.

(23) Diehl, C.; Černoch, P.; Zenke, I.; Runhe, H.; Pitschke, R.; Hartmann, J.; Tiersch, B.; Schlaad, H. Soft Matter 2010, 6, 3784-3788.

(24) Weber, C.; Becer, C. R.; Hoogenboom, R.; Schubert, U. S. Macromolecules 2009, 42, 2965-2971.

(25) Weber, C.; Becer, C. R; Guenther, W.; Hoogenboom, R.; Schubert, U. S. Macromolecules 2010, 43, 160-167.

(26) Rueda, J. C.; Zschoche, S.; Komber, H.; Krahl, F.; Arndt, K.-F.; Voit, B. Macromol. Chem. Phvs. 2010, 211, 706-716.

(27) Grayson, M. S.; Godbey, W. T. J. Drug Targeting 2008, 329-356.

(28) Del Villano, L.; Kommedal, R.; Fijten, M. W. M.; Schubert, U. S.; Hoogenboom, R.; Kelland, M. A. Energy Fuels 2009, 23, 3665.

(29) Witte, H.; Seeliger, W. Ann. Chem.-Justus Liebig 1974, 6, 996-1009.

(30) Hoogenboom, R; Fijten, M. W. M.; Thijs, H. M. L.; van Lankvelt, B. M.; Schubert, U. S. Des. Monomers Polvm. 2005, 8, 659-671.

(31) Lobert, M.; Kohn, U.; Hoogenboom, R.; Schubert, U. S. Chem. Commun. 2008, 1458-1460.

(32) Ouvrard, C.; Berthelot, M.; Laurence, C. J. Chem. Soc., Perkin Trans. 1999, 2, 1357-1362.

(33) Wiesbrock, F.; Hoogenboom, R.; Leenen, M. A. M.; Meier, M. A. R.; Schubert, U. S. Macromolecules 2005, 38, 5025-5034.

(34) Meeussen, F.; Nies, E.; Berghmans, H.; Verbrugghe, S.; Goethals, E.; Du Prez, F. Polvmer 2000, 41, 8597-8602.

(35) Bloksma, M. M.; Bakker, D. J.; Weber, C.; Schubert, U. S.; Hoogenboom, R. Macromol. Rapid Commun. 2010, 31, 724-728.

(36) Tam, K. C.; Wu, X. Y.; Pelton, R. H. Polvmer 1992, 33, 436-438.

(37) Hadjichristidis, N.; Pitsikalis, M.; Iatrou, H.; Pispas, S. Macromol. Rapid Commun. 2003, 24, 979-1013. 